\title{
HOW SHOULD WE CARE FOR PATIENTS WHO ARE NOT YET ELIGIBLE FOR ART?
}

\author{
Tom H Boyles ${ }^{1,2}$, MA, BM BCh, MRCP, DTM\&H, MD \\ Lynne S Wilkinson ${ }^{1,3}, B A, L L B$ \\ ${ }^{1}$ Madwaleni Hospital, E Cape \\ ${ }^{2}$ Division of Infectious Diseases and HIV Medicine, Department of Medicine, Groote Schuur Hospital and University of Cape Town \\ ${ }^{3}$ Médecins Sans Frontières, Cape Town
}

In 2009, there were an estimated 5.6 million people living with HIV in South Africa. ${ }^{1}$ Based on a threshold of CD4 $<350 \mathrm{cells} / \mathrm{\mu l}$, it is estimated that around $46 \%$ of patients are not yet eligible for antiretroviral therapy (ART). ${ }^{2}$ The Department of Health guidelines from $2010^{3}$ have limited recommendations for the care of patients not eligible for ART. There is no guidance on how to develop a package of care or how roles should be assigned between different cadres of staff. It is unclear whether pre-ART care services are currently being offered to large numbers of patients, and it is our opinion that comprehensive guidelines based on effective models of pre-ART care are urgently needed. We believe that this has the potential to reduce morbidity, mortality and transmission and increase long-term retention in care in South Africa.

Currently, rates of retention in pre-ART care are disappointing. A recent review of studies from subSaharan Africa found that the median proportion of patients lost to care was $59 \%$ between testing and receipt of CD4 counts, $46 \%$ between staging and ART eligibility, and $68 \%$ between ART eligibility and initiation. ${ }^{4}$ Based on the information available, only about $18 \%$ of patients who are not yet eligible for ART when diagnosed with HIV remain continuously in care until ART eligibility. Although some patients may enter care elsewhere, others may only present again when unwell and some time after becoming eligible for ART. The median starting CD4 count of patients in South Africa remains well below the level at which patients become eligible for $A R T,{ }^{5-6}$ and loss to care of ineligible patients is likely to be an important contributor to this. Low CD4 nadir is associated with poor clinical outcomes ${ }^{7}$ and increased costs. ${ }^{8}$ In response, calls have been made for significantly improved adherence to pre-ART care and monitoring of patients not yet eligible for ART to achieve AIDS strategy goals and reduce the problem of late presentation and initiation of ART. ${ }^{9}$

One reason for low retention in care in the pre-ART period may be lack of availability of comprehensive HIV care services. Patients simply asked to return for repeat CD4 testing after 6 months may be less inclined to return than patients offered a comprehensive service package upon diagnosis. Another reason may be a perception among patients that ART is only necessary as a last resort when becoming sick despite other attempts to remain well while living with HIV. The 2003 World Health Organization (WHO) recommendations for ART in resource-limited settings were to start ART when the CD4 count dropped to $\leq 200$ cells/ $\mu$ l or the patient developed WHO stage 4 illness. ${ }^{10}$ This message was interpreted by many as ART only being necessary when one becomes sick. Many people's only experience of ART was seeing it prescribed to sick and late-presenting patients, which served to reinforce the misunderstanding. The 2010 WHO recommendations (adopted by South Africa in August 2011) that all patients with a CD4 $\leq 350$ cells/ $\mu$ initiate $A R T^{11}$ were widely welcomed by campaigners. However, there was a word of caution from Vuyiseka Dubula, the General Secretary of the Treatment Action Campaign in South Africa, who explained: '... our communities were made to believe we only needed ART when we were sick, now we have a massive task ahead of us to change deeply entrenched community perceptions' (personal communication). It may take some time for communities to buy into the importance of accessing ART early, and engagement of patients not yet eligible for ART is an ideal forum to begin.

Our own service model in the rural Eastern Cape province of South Africa provides an example of how effective comprehensive HIV services including preART care can be delivered. ${ }^{12}$ Outcomes analysis of 1803 patients initiating ART found that the 270 who had received $>6$ months pre-ART care started ART at higher CD4 counts than the cohort as a whole (192 v. 123). Notably, receiving $>6$ months pre-ART care was independently associated with clinically relevant outcomes including a $50 \%$ reduction in both mortality and loss to follow-up (LTFU) after starting ART. This was an observational study with some selection bias, as the pre-ART care group were included as a result of being adherent to the pre-ART care programme for at least 6 months. This is more likely to explain the differences in LTFU than those in starting CD4 count and mortality. Data from the private sector in South Africa also show that patients receiving pre-ART care incur lower overall direct costs. $^{13}$

Our service model focuses on engaging patients in peer educator-led community care groups immediately upon testing positive, regardless of eligibility for ART. Groups are run on a weekly basis and are decentralised to local primary healthcare clinics with patients usually choosing 
to attend the group nearest their home. Meetings begin with group education around a specific topic facilitated by a peer educator; examples include the importance of ART adherence and the long-term side-effects of ART. Each patient has a paper file held at the clinic, and at each attendance the peer educators record weight and replies to specific screening questions about tuberculosis and sexually transmitted infection (STI), and ask whether there are any other symptoms. Patients with weight loss or any symptoms are referred to the clinic nurse on the same day. Pre-ART patients are prescribed multivitamins or co-trimoxazole and counts of returned pills are used to assess readiness for ART. Peer educators also provide one-on-one counselling for patients preparing for ART.

Groups are fully integrated between those on ART and those who are not yet eligible. This approach has allowed groups to grow quickly and may have reduced HIV-related stigma in the community. Depression is common following a diagnosis of HIV and may be worse in areas with high levels of stigma. ${ }^{14-15}$ Depression is associated with both reduced linkage to care and impaired adherence to $A R T,{ }^{16}$ but can be effectively treated with interpersonal support group therapy. ${ }^{17}$ The formation of community support groups of patients who have disclosed their HIV status to the group may prevent depression and improve retention in care in newly diagnosed patients. Incentives to remain in longterm pre-ART care include the provision of prophylactic medication such as isoniazid preventive therapy (IPT), access to screening services such as Pap smears, and inclusion in the social activities associated with joining a community group.

Until universal ART coverage is achieved in South Africa it is likely that resources will predominantly be concentrated on ART delivery, and it is important that pre-ART services are delivered in the most resourceefficient way. In our service model the majority of tasks are performed by lay counsellors. Referrals to nurses are only made for specific clinical reasons (Fig. 1). While our care groups are run on clinic premises, it would be preferable to move them out of the clinic altogether and into the community. Innovative approaches to community-led pre-ART care could be adapted from successful community ART models, which have been shown to reduce the burden on healthcare facilities and achieve higher rates of retention in care. ${ }^{18}$

The WHO recommends at least 6 months of IPT for all HIVpositive adolescents and adults with latent tuberculosis, whether or not on ART. ${ }^{19}$ By the end of 2009, only around 85000 people with HIV had received IPT, representing $<0.3 \%$ coverage worldwide. ${ }^{20} \mathrm{ART}$-ineligible patients are a large group who could be targeted to increase IPT coverage. IPT is an ideal component of pre-ART care as it provides a tangible treatment option and allows monitoring of adherence issues. Distribution of free cotrimoxazole has been shown to decrease loss to followup in patients not yet eligible for ART, ${ }^{21}$ and it is likely that IPT would have a similar effect. Prescribing IPT in the pre-ART period reduces the risk of overlapping drug toxicities and high pill burden once ART is commenced. Additional benefits are that active tuberculosis must be ruled out before prescribing IPT, which increases active case finding.

Proven HIV prevention interventions to be included in pre-ART care include treatment for sexually transmitted infections after symptom screening by lay counsellors, ${ }^{22}$ condom promotion and distribution, ${ }^{23}$ contraception ${ }^{24}$ and pregnancy planning services. ${ }^{25}$ Initiating ART at CD4 counts $>350 \mathrm{cells} / \mu \mathrm{l}$ for patients in serodiscordant couples is a highly effective prevention strategy ${ }^{26}$ that could be implemented more easily if patients were retained in active pre-ART care.

Improved patient preparation has been shown to improve retention in care rates on $\mathrm{ART} .{ }^{27}$ Patients who are ineligible for ART at the time of diagnosis may benefit from extended ART preparation, giving them extra time to adjust to the need for lifelong therapy and to attend multiple group education sessions. Early preparation and retention of ineligible patients also allows programmes to respond quickly to changes in eligibility criteria.

There are many challenges to providing comprehensive HIV services and more data are required to inform us of the cost and benefits. It is unlikely that a single model will be appropriate for all settings, and consultation with patients should guide local programme models.

\begin{tabular}{|l|}
\hline Tasks of peer educators \\
\hline 1. ART adherence counselling \\
\hline 2. CD4 monitoring according to guidelines \\
\hline 3. TB \& STI symptom screening \\
\hline 4. Refills of isoniazid \& co-trimoxazole \\
\hline 5. Distribution and promotion of condoms \\
\hline 6. Weight monitoring \\
\hline $\begin{array}{l}\text { 7. Prolonged psycho-social ART preparation and HIV } \\
\text { education }\end{array}$ \\
\hline 8. Provide nutritional supplementation \\
\hline
\end{tabular}

\begin{tabular}{|l|}
\hline Tasks of nurses \\
\hline 1. ART initiation \\
\hline 2. IPT initiation \\
\hline $\begin{array}{l}\text { 3. Management of symptomatic patients or those } \\
\text { losing weight }\end{array}$ \\
\hline 4. Pregnancy testing and care \\
\hline 5. Pap smears \\
\hline 6. Blood taking \\
\hline 7. Contraceptive services \\
\hline
\end{tabular}

Fig. 1. Service package delivered in pre-ART services by various cadres of staff. 
Our experience suggests that important features in any setting will be delivering services close to people's homes or jobs, integrating services with those of patients already on ART, and task shifting to appropriate cadres of staff. Our opinion is that no time should be wasted in integrating active management of patients not yet eligible for ART into programme models. We believe this can have a major public health impact by reducing morbidity, mortality and transmission and by increasing long-term retention in care. Furthermore, this can be achieved without overburdening an already stretched healthcare service.

The authors declare no conflicts of interest.

\section{REFERENCES}

1. UNAIDS. Global Report: UNAIDS report on the global AIDS epidemic 2010. 2010 http://www.unaids.org/documents/20101123_GlobalReport_em.pdf (accessed 6 December 2010).

2. Adam MA, Johnson LF. Estimation of adult antiretroviral treatment coverage in South Africa. S Afr Med J 2009:99:661-667.

3. Department of Health. The South African Antiretroviral Treatment Guidelines, 2010. 2010. http://www.doh.gov.za/docs/factsheets/guidelines/art.pdf (accessed 20 june 2011).

4. Rosen S, Fox MP. Retention in HIV care between testing and treatment in subSaharan Africa: a systematic review. PLoS Med 2011;8(7):e1001056.

5. Boulle A, Van Cutsem G, Hilderbrand K, et al. Seven-year experience of a primary care antiretroviral treatment programme in Khayelitsha, South Africa. AIDS 2010;24(4):563-752

6. Cornell M, Grimsrud A, Fairall L, et al. Temporal changes in programme outcomes among adult patients initiating antiretroviral therapy across South Africa, 2002-2007. AIDS 2010;24(14):2263-2270

7. Severe P, Juste MA, Ambroise A, et al. Early versus standard antiretroviral therapy for HIV-infected adults in Haiti. N Engl J Med 2010;363(3):257-265.

8. Leisegang R, Cleary S, Hislop M, et al. Early and late direct costs in a Southern African antiretroviral treatment programme: a retrospective cohort analysis. PLoS Med 2009;6(12):e1000189.

9. Larson BA, Brennan A, McNamara L, et al. Early loss to follow up after enrolment in pre-ART care at a large public clinic in Johannesburg, South Africa. Trop Med Int Health 2010:15(suppl 1):43-47.

10. World Health Organization. Scaling up antiretroviral therapy in resource-limited settings: Treatment guidelines for a public health approach. Geneva: World Health Organization, 2003. http://whqlibdoc.who.int/publications/2004/9241591552.pdf (accessed 24 November 2010).
11. World Health Organization. Antiretroviral therapy for HIV infection in adults and adolescents. Recommendations for a public health approach. 2010 revision. 2010. http://whqlibdoc.who.int/publications/2010/9789241599764_eng.pdf (accessed 20 June 2011).

12. Boyles TH, Wilkinson LS, Leisegang R, Maartens $G$. Factors influencing retention in care after starting antiretroviral therapy in a rural South African programme. PLoS One 2011;6(5):e19201.

13. Leisegang R, Maartens G, Hislop M, Regensberg L, Cleary S. Improving the evidence base of Markov models used to estimate the costs of scaling up antiretroviral programmes in resource-limited settings. BMC Health Serv Res 2010;10(suppl 1):S3.

14. Bhatia R, Hartman C, Kallen MA, Graham J, Giordano TP. Persons newly diagnosed with HIV infection are at high risk for depression and poor linkage to care: Results from the Steps Study. AIDS Behav 2011;15(6):1161-1170.

15. Sorsdahl KR, Mall S, Stein DJ, Joska JA. Perspectives towards mental illness in people living with HIVIAIDS in South Africa. AIDS Care 2010;22(11):1418-1427.

16. Starace F, Ammassari A, Trotta MP, et al. Depression is a risk factor for suboptimal adherence to highly active antiretroviral therapy. J Acquir Immune Defic Syndr 2002;31(suppl 3):S136-139.

17. Heckman TG, Sikkema KJ, Hansen N, Kochman A, Heh V, Neufeld S. A randomized clinical trial of a coping improvement group intervention for HIV-infected older adults. J Behav Med 2011:34(2):102-111.

18. Decroo T, Telfer B, Biot M, et al. Distribution of antiretroviral treatment through selfforming groups of patients in Tete province, Mozambique. J Acquir Immune Defic Syndr 2011;56(2):e39-e44.

19. World Health Organization. Guidelines for intensified tuberculosis case finding and isoniazid preventative therapy for people living with HIV in resource constrained settings, 2010. 2010. http://whqlibdoc.who.int/publications/2011/9789241500708_ eng.pdf (accessed 6 December 2010).

20. World Health Organization. Global Tuberculosis Control, 2010. 2010. http://www. who.int/tb/publications/global_report/2010/en/index.html (accessed 6 December 2010).

21. Kohler PK, Chung MH, McGrath CJ, Benki-Nugent SF, Thiga JW, John-Stewart GC. Implementation of free cotrimoxazole prophylaxis improves clinic retention among ART-ineligible clients in Kenya. AIDS 2011;25(13):1657-1661.

22. Dallabetta G, Neilson G. Efforts to control sexually transmitted infections as a means to limit HIV transmission: what is the evidence? Curr HIVIAIDS Rep 2004;1(4):166-171.

23. Padian NS, Buve A, Balkus J, Serwadda D, Cates W Jr. Biomedical interventions to prevent HIV infection: evidence, challenges, and way forward. Lancet 2008;372:585599.

24. Wilcher R, Petruney T, Reynolds HW, Cates W. From effectiveness to impact: contraception as an HIV prevention intervention. Sex Transm Infect 2008;84(suppl 2):ii54-60.

25. Aaron EZ, Criniti SM. Preconception health care for HIV-infected women. Top HIV Med 2007;15(4):137-141

26. Cohen MS, Chen YQ, McCauley M, et al. Prevention of HIV-1 infection with early antiretroviral therapy. N Engl J Med 2011;365(6):493-505.

27. Coetzee D, Boulle A, Hildebrand K, Asselman V, Van Cutsem G, Goemaere E. Promoting adherence to antiretroviral therapy: the experience from a primary care setting in Khayelitsha, South Africa. AIDS 2004;18(suppl 3):S27-31. 